\title{
Celestino Gorostiza y el teatro experimental en México
}

$\mathrm{A}^{\mathrm{UE}}$ Celestino Gorostiza quien creó las justas proporciones - del teatro experimental en México. Sus años de profesor de práctica escénica en el Conservatorio Nacional, su sentido autocrítico, y su preparación cultural, hicieron posible el desarrollo de su teatro. Su amor hacia el teatro se había manifestado en diversas formas, como actor y director en el Teatro de Ulises en 1928, al mismo tiempo como traductor de algunas piezas del teatro universal, y como crítico teatral del semanario El Espectador. En 1932 fundó el Teatro Orientación, bajo el patrocinio de la Secretaría de Educación Pública y Bellas Artes.

Gorostiza logró reunir, con unos cambios, al grupo de Ulises, para su nuevo experimento. Este grupo ya reorganizado tenía una nueva revista literaria, Contemporáneos, a la que dieron un carácter particular. "El prestigio de ella nació de la reunión en sus páginas -escribe Antonio Magaña Esquivel- de firmas representativas de una nueva prosa, de una nueva poesía, en México y Europa; prestigio que confirmaba la disciplina de los escritores jóvenes que aparecían al frente del grupo."1

Estas relaciones de solidaridad alcanzaron al Teatro Orientación e influyeron en su prestigio. "Orientación heredó a su vez el rigor crítico, el respeto a la cultura, la severidad y la disciplina, la inclinación hacia el conceptismo y el des-

1 Imagen del teatro (México, 1940), pág. 90. 
precio hacia los elementos dramáticos o melodramáticos de fácil éxito teatral."2 Era un teatro literario, culto, e inteligente.

El repertorio de Orientación hacía visible una estricta selección y un buen gusto: Donde está la cruz, de Eugene O'Neill; Antigona, de Sófocles; Intimidad, de Jean-Víctor Pellerin; Jorge Dandin, o El marido fracasado, de Moliére; Cuento de amor, de Shakespeare; Una petición de mano, de Chejov; La boda del calderero, de John Synge; Entremés del viejo celoso, de Cervantes; y Knock, o El triunfo de la medicina, de Romains.

Se excluyó a la masa del público para crearse uno en el que la fidelidad y la calidad fuesen los mejores sustentos. Se rechazó toda concesión al gusto corriente. De junio a diciembre se presentó la primera temporada; la segunda vino inmediatamente después, en febrero de 1933, en la misma sala de la Secretaría de Educación Pública. Se organizó un nuevo repertorio: El matrimonio, de Gogol; Amadeo, o Los Caballeros en fila, de Romains; Su esposo, de Shaw; y Macbeth, de Shakespeare.

Obtenido ya el repertorio y el suficiente dominio de sus propósitos, el Teatro Orientación salía a la calle y se acomodó en el Teatro Hidalgo. Deseaba presentar al público los resultados positivos de sus experiencias ya sancionados por el público fiel del pequeño salón experimental. Las obras son las mismas ya representadas, en su mayoría, aunque añaden dos piezas mexicanas: obras originales de Villaurrutia, Parece mentira; 3 y de Gorostiza, La escuela del amor.4 Agustín Lazo y Julio Castellanos se consagraron como escenógrafos y una "constelación de actores -Clementina Otero, Carlos López Mogtezuma, Josefina Escobedo, Stella Inda, Víctor Urruchúa, Ramón Vallarino y tantos otros que han logrado abrirse paso en el teatro y en el cine- encontró en el Teatro de Orientación su verdadera cuna."5

2 Magaña Esquivel, op. cit., pág. 91.

3 (México, 1934).

4 (México, 1935).

5 "Apuntes para una historia del teatro experimental", México en el Arte, nưm. 10-11, Instituto Nacional de Bellas Artes, México, 1950, pág. 26. 
En agosto de 1934 se inició la cuarta temporada de Orientación, que duró hasta septiembre. En esta temporada se veía el predominio de la producción dramática mexicana sobre la extranjera en el repertorio: del teatro extranjero solamente estrenaron dos piezas, $A$ la sombra del mal, de Lenormand, y Lilion, de Franz Molnar; y del mexicano, cuatro piezas, $E l$ barco, de Carlos Díaz Dufoo Jr.; Ifigenia cruel, de Alfonso Reyes; ¿ En qué piensas?, de Xavier Villaurrutia; y Ser o no ser, de Celestino Gorostiza. "Tres años de trabajo constante, tesonero, incansable, -dice Celestino Gorostiza- dieron a México una visión panorámica del teatro universal de todos los tiempos, desde Grecia y el Siglo de Oro español hasta los Estados Unidos y México..."6

La mejor prueba del buen éxito del Teatro Orientación era que "había comenzado a crear una conciencia teatral, un público teatral nacido en el buen gusto, un grupo de actores y actrices con sentido nuevo de la interpretación, y nuevos autores dramáticos."7

Después de la temporada de 1934 el Teatro Orientación detuvo su tarea. No obstante, este teatro conservaba una vida virtual a través del mismo grupo de escritores sujetos a la misma idea teatral. Esto explica la confianza de Celestino Gorostiza, al alcanzar la jefatura del Departamento de Bellas Artes, en la posibilidad de recrear, después de cuatro años de silencio, su teatro experimental.

En 1938 anunció una segunda época de Orientación que encontró reunidos a tres directores: Xavier Villaurrutia, Julio Bracho y Rodolfo Usigli, cada uno responsable de un repertorio $y$ de un grupo de actores no profesionales. Lo que distinguió esta segunda época era su nueva organización. Se quiso respetar las relaciones entre cada director, su repertorio y sus actores, y establecer al mismo tiempo un denominador común de cordialidad en las actividades de los tres grupos experimentales. Pero escribe Magaña Esquivel, "No obstante el hilo conductor que unía y coordinaba el trabajo de los dos grupos, la manera de poner en equilibrio los elementos que

i Gorostiza, op. cit., pág. 26.

7 Magaña Esquivel, op. cit., pág. 96. 
se requieren para producir una buena representación hacía visible diversidad de estilos, de espíritus, en los directores directamente responsables de estas dos piezas, Villaurrutia y Bracho."8

El tercer grupo experimental, organizado bajo la dirección de Rodolfo Usigli, no se presentó en esta temporada de Bellas Artes. Pasados unos meses, ya en 1939, hizo su presentación en el escenario del Teatro Hidalgo con una pieza de Behrman, Biografia, traducida por el propio Usigli.

En resumen, el Teatro Orientación ponía en movimiento los elementos esenciales para hacer madurar una conciencia teatral en México. "¿Y qué otra cosa fueron los teatros experimentales de Ulises y Orientación sino las tentativas de crear un público, una curiosidad nuevos, que resistieran nuevas obras, extranjeras y mexicanas?"'9

Al principio, Celestino Gorostiza, como autor dramático, ensayó la traducción de obras del teatro extranjero. A las traducciones sucedieron El nuevo paraíso,10 La escuela del amor, Ser o no ser, 11 piezas originales. Son dramas construídos con plena conciencia de las reglas, problemas y limitaciones del arte escénico. En 1939 publicó su comedia Escombros del sueño, en tres actos, y en 1943 estrenó otra llamada La mujer ideal.

Detenidos los trabajos de Orientación por circunstancias interiores de la Secretaría de Educación Pública, que lo sostenía económicamente, Gorostiza era solicitado por el cine, y se le encargó la dirección artística de la Cinematográfica Latino Americana, que ejercía durante dos años, 1935 y 1936. Un año más tarde la Compañía de María Tereza Montoya le nombró su director artístico, en una temporada en Bellas Artes.

En 1938, al frente del Departamento de Bellas Artes, Gorostiza reanudó sus actividades teatrales. Buscó fortalecer y ampliar, como queda dicho, los caminos originales del Teatro Orientación.

8 Ibid., pág. 99.

9 Xavier Villaurrutia, Textos y pretextos (México, 1940), pág. 179.

10 Publicado en Contemporáneos, II, núm. 17, octubre de 1929, págs. 177-209.

11 (México, 1955). 
Durante los últimos años ha adquirido el primer lugar entre los dramaturgos mexicanos por su continuo trabajo. Por su última pieza, El color de nuestra piel,12 recibió el premio Ruiz de Alarcón otorgado por la Agrupación de Críticos de Teatro de México, como la mejor comedia mexicana estrenada en 1952. Su obra más reciente, que está para aparecer, es Columna social, sátira sobre ciertos grupos sociales que aspiran a figurar en las notas sociales de los periódicos bajo un falso aspecto intelectual.

Ahora como Jefe del Departamento de Teatro del Instituto Nacional de Bellas Artes, se revela como magnífico organizador de todas las actividades teatrales de la República. Ya hay grupos experimentales en México que tienen público y presentan con éxito las mejores obras del teatro universal, pero vacilan en presentar obras mexicanas. Por eso, Celestino Gorostiza ha organizado una asociación de los directores más importantes de estos grupos para facilitar la presentación de dramas mexicanos. También ha efectuado concursos de grupos teatrales del Distrito Federal y de los Estados para tales fines.

\author{
RUTH LAMB, \\ Scripps College.
}

\title{
BIBLIOGRAFIA
}

Jorge Cuesta, "Introducción", a Ser o no ser, de Celestino Gorostiza (México, 1935), págs, 3-8.

Celestino Gorostiza, "Apuntes para una historia del teatro experimental", México en el Arte, núm. 10-11, Instituto Nacional de Bellas Artes, México, 1950.

—, "Lo blanco y lo negro, Carta a Xavier Villaurrutia", Letras de México, I, núm. 1, 15 de enero, 1943, págs. $6,8$.

Miguel Guardia, "The Mexican Theater: Celestino Gorostiza," Mexican Cultural Bulletin, núm. 15, julio de 1953, pág. 3.

Antonio Magaña Esquivel, "Celestino Gorostiza, director y comediógrafo", Letras de México, II, núm. 16, 15 de abril, 1940, pág. 6 .

- Imagen del teatro (México, 1940).

Xavier Villaurrutia, Textos y pretextos (México, 1940).

12 (México, 1953). 
